\title{
Concrescence of impacted mandibular third molar with a fourth molar
}

\author{
Arun Kumar K.V'1, Deepa D²
}

Professor ${ }^{1}$, Department of Oral \& Maxillofacial Surgery, Subharti Dental College and Hospital, NH-58, Delhi-Haridwar By-pass road Meerut-250005, Uttar Pradesh.

Professor $^{2}$ Department of Periodontology

\begin{abstract}
:
Concrescence is a developmental anomaly of tooth in which fusion between two completely formed roots takes place at the cementum. It may involve either deciduous or permanent teeth. Concrescence is mostly observed in maxillary than in mandibular teeth. A rare case of impacted mandibular third molar fused with a supernumerary molar has been reported here.
\end{abstract}

Keywords: Concrescence, Developmental anomaly, Impacted, Mandibular third molar, Supernumerary tooth.

\section{Introduction}

Concrescence occurs when the roots of two or more primary or permanent teeth are fused by cementum. If the condition occurs during development, it is sometimes referred to as true concrescence and if later then it is termed as acquired concrescence. The exact aetiology is unknown. However, it is assumed to be due to space restriction during development, local trauma, excessive occlusal force, or local infection after development plays an important role. ${ }^{1}$

Concrescence is most frequently noted in maxillary molars, especially a third molar and a supernumerary tooth. ${ }^{2}$ The concrescence leads to a loss of gingival architecture leading to the development of funnels, which may cause plaque accumulation thus, resulting in periodontal tissue destruction, influences surgical procedures along with periodontal, endodontic diagnosis and treatment. Extraction of one tooth may result in the unintended removal of the second because the cementum bridge may not be well visualized radiographically. Here we present a rare case of concrescence in the mandible involving impacted third molar and supernumerary molar.

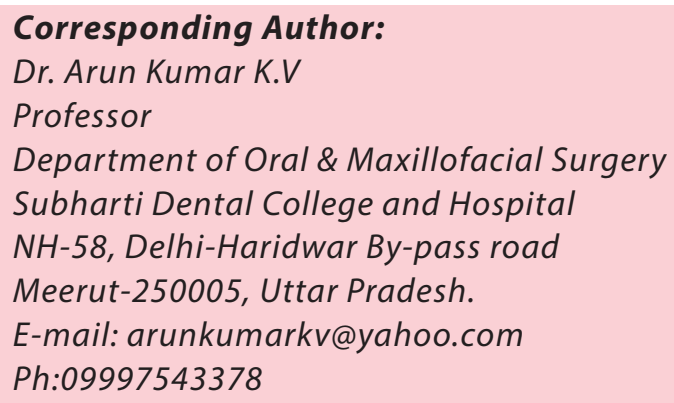

\section{Case report}

A male patient aged 28 years presented to the Department of Periodontology with a chief complaint of pain and mild swelling in the left lower back teeth region since seven days. Medical history revealed no significant health problems or trauma. There was no relevant family history of dental abnormalities. On clinical examination, there was mild swelling in the left lower back teeth region, with the tip of the impacted third molar visible in the oral cavity. Remaining teeth in the maxillary and mandibular arch were normal. Intra-oral periapical radiograph revealed the presence of an impacted mandibular third molar and a fourth molar distally (Fig. 1). Radiograph further revealed a concrescence between impacted third molar and supernumerary molar, with evident cementum which joined both teeth. Extraction was planned; both teeth were removed under local anaesthesia (Fig. 2 ). Both the teeth were removed together without a split. Wound was closed with a 3-0 silk suture. No complications like swelling or pain appeared after the extraction. Patient was called after 10 days for suture removal and healing was found to be satisfactory.

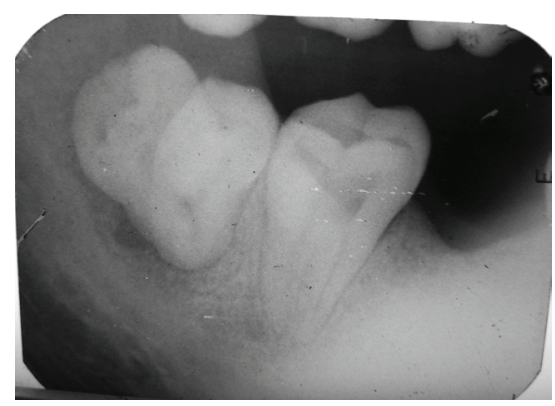

Fig.1: Intra oral periapical radiograph showing impacted mandibular third molar fused with a supernumerary molar. 


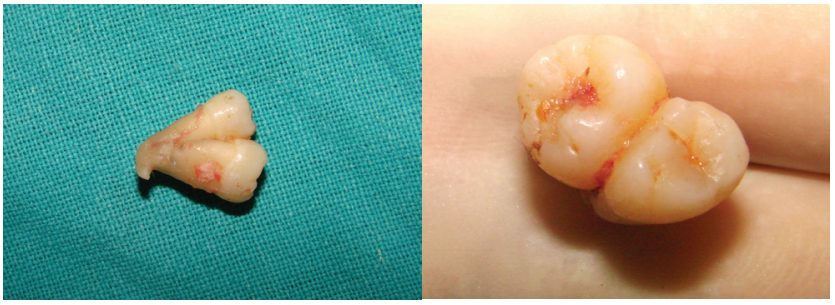

Fig. 2: Surgically removed impacted mandibular third molar fused with supernumerary molar.

\section{Discussion}

Concrescence represents a rare developmental anomaly in which two fully formed teeth are joined along the root surfaces by cementum. It is thought to arise as a result of traumatic injury or crowding of teeth with resorption of the interdental bone so that the two roots are in approximate contact and become fused by the deposition of cementum between them. Concrescence may occur before or after the teeth have erupted, and although it usually involves only two teeth, there are very few cases on record of union of three teeth by cementum. ${ }^{3}$ Maxillary molars are the teeth most frequently involved, especially a third molar and a supernumerary tooth. ${ }^{4}$ Further, very few cases have been reported about the concrescence of a third molar and a supernumerary tooth. ${ }^{5}$ This case is an uncommon concrescence due to its occurrence in the mandible. The diagnosis could frequently be established by radiographic examination. These when unnoticed before extraction may end up removal of the adjacent fused tooth too. Hence, it is necessary that the dentist be forewarned of the condition so that patient is informed regarding possible collateral damage.

The management of supernumerary teeth depends on many factors, including their potential effect on the developing normal dentition, their position and number, and the potential complications that may result from surgical intervention. If supernumerary teeth erupt, they can cause malalignment of the normal dentition. Those that remain in the jaws may cause root resorption and their follicles develop into dentigerous cyst or interfere with the normal eruption sequence. All the preceding factors influence the decision to either remove a supernumerary tooth or keep it under observation. Several approaches are available for the treatment of concrescence and the treatment of choice is determined by the patient's needs. If the union does not affect aesthetics or cause eruption pathologies, no treatment is required. ${ }^{2,5,6,7}$ In this case repeated pain episodes lead to the decision of extraction of involved teeth. Additionally, selective shaping with or without placement of full crowns has been performed although some cases exhibit pulpal or coronal anatomic features that prevent reshaping and require surgical removal with prosthetic replacement. ${ }^{7}$

Concrescence affects treatment only when the decision is made to remove one or both of the involved teeth because this condition complicates the extraction. But, in this case presented here, both had to be removed since both were impacted.

\section{Conclusion}

The occurrence of fourth molar in the mandibular arch is an uncommon phenomenon. This condition is often undetected in routine dental examinations, particularly when situated distally to the second molar. The treatment decision has to be based on the merits and demerits of conservative $\mathrm{v} / \mathrm{s}$ surgical procedures in the best interest of patient.

\section{References:}

1. White SC, Pharoah MJ. Dental anomalies. Oral radiology, principles and interpretation.2009, 6th edition, Elsevier publishers, New Delhi, Pg.No. 301.

2. Goaz W, White S. Oral radiology. 3rd ed. Philadelphia: Mosby 1994: Pg No. 348-349.

3. Sharma U, Gulati A, Gill NC. Concrescent triplets involving primary anterior teeth. Contemp Clin Dent 2013;4:94-6.

4. Gunduz L, Sumer M, Sumer AP, Gunhano. Concrescence of a mandibular third molar and a supernumerary fourth molar. Report of a rare case. British Dent J 2000;200:141-142.

5. Romito L. Concrescence: Report of a rare case. Oral Surg Oral Med Oral Pathol Oral Radiol Endod 2004; 97: 325-327.

6. Kilian M, Croll T. Dental twinning anomalies: the nomenclature enigma. Quint Int 1990;21:571-576.

7. Shafer WG, Hine MK, Levy BM, Tomich CA. Text Book of Oral Pathology. Philadelphia: Saunders 1983, Pg. No. 38-40.

How to cite this article:

Arun Kumar KV, Deepa D. Concrescence of impacted mandibular third molar with a fourth molar - A Rare Case Report. CODS J Dent 2015; 7: 48 - 49.

Source of support: Nil. Conflict of interest: None Declared. 